\title{
Media Pembelajaran Biologi Berbentuk Infografis Tentang Materi Sistem Imun Pada Manusia
}

\section{Indra Putra ${ }^{*}$}

${ }^{1}$ Jurusan Biologi, Universitas Negeri Padang, Padang, Indonesia

\section{ART ICLE INFO}

Article history:

Received August 09, 2021

Revised August 10, 2021

Accepted September 30, 2021

Available online October 25, 2021

Kata Kunci:

Media Pembelajaran, Infografis,

System Imun

Keywords:

Learning Media, Infographic, Immune System

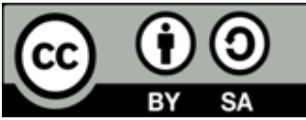

This is an open access article under the CC BY-SA license.

Copyright (ㅇ 2021 by Author. Published by Universitas Pendidikan Ganesha.

\begin{abstract}
A B S T R A K
Kurangnya penggunaan media pembelajaran yang dapat digunakan dalam pembelajaran Biologi materi sistem sistem imun pada manusia. Hal ini menyebabkan siswa kesulitan dalam memahami materi pembelajaran. Penelitian ini bertujuan untuk mengembangkan media pembelajaran biologi berupa infografis tentang sistem imun manusia. Jenis penelitian yang digunakan adalah penelitian R\&D (riset dan pengembangan). Kelayakan produk media pembelajaran berupa infografis diukur berdasarkan validitas media dan kepraktisan media. Subjek penelitian ini adalah 35 peserta didik dan seorang guru biologi. Media pembelajaran berupa infografis divalidasi oleh 2 orang dosen biologi dan 1 orang guru biologi. Metode analisis data dilakukan dengan statistik deskriptif meliputi analisis validitas dan praktikalitas. Berdasarkan hasil analisis validasi, persentase validator ahli adalah $88,11 \%$ dan dapat dikatakan valid. Hasil uji kepraktisan oleh guru diperoleh persentase $85 \%$ memenuhi kriteria praktik, dan hasil uji praktikalitas siswa diperoleh persentase $85,24 \%$ memenuhi kriteria praktik. Berdasarkan hasil tersebut, media pembelajaran biologi yang dikembangkan dalam bentuk infografis telah memenuhi aspek kegunaan sebagai media pembelajaran yang valid dan praktis. Media pembelajaran infografis dapat membantu siswa dalam belajar sehingga siswa lebih memahami materi pembelajaran dengan mudah.
\end{abstract}

\section{A B S T R A C T}

Lack of learning media can be used in Biology learning material on the human immune system. It causes students difficulty in understanding the learning material. This study aims to develop biology learning media in infographics about the human immune system. The type of research used is $R \& D$ research (research and development). The feasibility of learning media products is measured based on the validity of the media and the practicality of the media. The subjects of this study were 35 students and a biology teacher. Learning media in infographics was validated by two biology lecturers and one biology teacher. The method of data analysis was carried out with descriptive statistics, including analysis of validity and practicality. Based on the results of the validation analysis, the percentage of expert validators is $88.11 \%$ and can be said to be valid. The results of the practicality test by the teacher were obtained by the percentage of $85 \%$ meeting the practice criteria, and the students' practicality test results obtained by the percentage of $85.24 \%$ meeting the practice criteria. Based on these results, the biology learning media developed in infographics has met the usability aspect as a valid and practical learning media. Infographic learning media can help students learn so that students understand the learning material more efficiently.

\section{PENDAHULUAN}

Pendidikan erat kaitannya dengan proses pembelajaran. Pembelajaran adalah interkasi yang dilakukan oleh guru dan peserta didik untuk mencapai tujuan pembelajaran (Fitriana et al., 2014; Pambudi et al., 2019; Rahma \& Pujiastuti, 2021). Tercapainya tujuan pembelajaran di Indonesia tidak lepas dari peran kurikulum. Pemerintah Indonesia saat ini menerapkan kurikulum 2013. Pembelajaran yang efektif adalah pembelajaran yang berlangsung aktif dan mampu menjadikan siswa semangat dalam pembelajaran (Novika Auliyana et al., 2018; Suadnyana et al., 2017). Pembelajaran yang aktif mampu 
meningkatkan motivasi siswa untuk terus menjadi pribadi yang lebih baik melalui proses pembelajaran. Salah satu pembelajaran yang didapatkan siswa yaitu Biologi. Biologi berkaitan dengan cara mencari tahu dan memahami tentang alam secara sistematis melalui proses penemuan (Berutu \& Tambunan, 2018; Dwipayana, 2013). Dalam mencapai tujuan pembelajaran agar lebih optimal, maka diperlukan suatu media pembelajaran (Ayuni et al., 2017; Seika Ayuni et al., 2017; Surata et al., 2020). Dengan menggunakan media pembelajaran diharapkan dapat membantu siswa untuk memahami pembelajarn tentang sistem imun pada manusia (Rofiq et al., 2019; Setianingsih et al., 2019).

Namun kenyataannya berdasarkan hasil observasi ke salah satu sekolah yaitu SMA Negeri 7 Padang, ditemukan bahwa banyak siswa yang tidak memahami materi pembelajaran disebabkan oleh kurangnya media pembelajaran yang memfasilitasi siswa dalam belajar sehingga berdampak terhadap tingkat pemahaman materi pembelajaran yang rendah (Herayanti et al., 2017; Priyanti et al., 2017; Wulandari et al., 2020). Ditemukan juga pada proses belajar mengajar guru menggunakan media pembelajaran berupa video yang diambil dari youtube dan gambar dari internet, namun media berupa video ini memberatkan peserta didik dengan besarnya penggunaan kuota dalam proses pembelajaran. Terdapat juga media yang dibuat dengan kertas karton, namun tidak sering digunakan. Pada pengamatan juga terlihat bahwa peserta didik lebih dominan dalam menggunakan bahan ajar berupa buku teks dari kemdikbud dan lembar kerja peserta didik (LKPD).

Berdasarkan permasalahan tersebut solusi yang dapat dilakukan yakni dengan mengemas pembelajaran dengan menggunakan media pembelajaran berbentuk infografis. Selama kegiatan pembelajaran, seorang guru dituntut selektif dalam pemilihan media pembelajaran agar materi yang disampaikan menjadi lebih bermakna, dapat diterima, dipelajari dan dipahami peserta didik (Pradilasari et al., 2019; Septiani \& Hasanah, 2019; Sulfemi, W. B., \& Mayasari, 2019). Pemilihan media pembelajaran harus disesuaikan dengan karakteristik peserta (Dewi et al., 2019; Handayani et al., 2017; Krismasari et al., 2019). Media pembelajaran sendiri bersifat mandiri, menjelaskan tujuan instruksional yang akan dicapai, memotivasi dan mengantisipasi kesukaran siswa dengan menyediakan bimbingan belajar, memberi latihan yang cukup, menyediakan rangkuman, dan berorientasi kepada siswa secara individual (Octaviani, 2017; Prabawa \& Restami, 2020; Pramana \& Suarjana, 2019). Media pembelajaran merupakan alat bantu yang digunakan untuk menyampaikan pesan atau informasi dalam pembelajaran.

Media pembelajaran saat ini mengalami perkembangan karena adanya pengaruh dari IPTEK (Alrwele, 2017; Azizul et al., 2020). Peserta didik memerlukan media pembelajaran yang bersifat baru agar proses pembelajaran tidak monoton (Arisantiani et al., 2017; Seika Ayuni et al., 2017; Wisada et al., 2019). Peserta didik akan tertarik dengan adanya variasi dalam bahan ajar, serta peserta didik juga lebih banyak mendapatkan kesempatan belajar secara mandiri di rumah dan mengurangi ketergantungan terhadap kehadiran guru (Apriansyah, 2020; Novika Auliyana et al., 2018; Priantini, 2020). Kegiatan yang dilakukan oleh peserta didik atas keinginan sendiri untuk belajar dengan atau tanpa bantuan guru, sehingga peserta didik dapat meningkatkan motivasi serta tanggung jawab terhadap dirinya sendiri disebut belajar mandiri. Salah satu media yang dapat digunakan dalam membantu peserta didik dalam belajar mandiri adalah melalui pengembangan media pembelajaran berbentuk infografis.

Infografis sebagai suatu media pembelajaran dapat menjadi salah satu cara yang dapat meningkatkan motivasi belajar peserta didik (Mansur \& Rafiudin, 2020; Wulandari et al., 2019). Media infografis ini dapat digunakan baik untuk belajar mandiri maupun belajar bersama dengan peserta didik lainnya. Infografis dapat meningkatkan minat baca peserta didik, karena adanya pemberian warna pada latar belakang, serta pemberian gambar yang relevan dan menarik (Arimbawa et al., 2018; Miftah et al., 2016). Kelebihan media infografis, yaitu pertama, media infografis memuat gambar-gambar dan kalimatkalimat yang menarik. Kedua, media infografis dapat ditampilkan di dalam platform media sosial seperti instagram. Ketiga, media infografis dapat diakses oleh siapapun termasuk peserta didik. Keempat, media infografis dapat memudahkan guru dalam penyampaian materi pembalajaran. Kelima, media infografis dapat meningkatkan imajinasi peserta didik. Media infografis juga dapat membantu pendidik untuk melatih kemampuan peserta didik dan kebiasaan peserta didik belajar secara mandiri. Media infografis berperan menyederhanakan informasi sehingga menjadi lebih mudah dan cepat dipahami (A. C. Dewi et al., 2021; Nasution \& Diansyah, 2020).

Kemampuan mengolah infografis akan menciptakan suasana pembelajaran yang atraktif bagi peserta didik, sehingga materi pembelajaran tersampaikan dengan baik kepada peserta didik. Media infografis merupakan satu diantara media informasi yang mudah disampaikan dan dapat dipahami dengan baik (Hakim \& Ramadhan, 2020; Muthiadin et al., 2020). Hal ini sesuai dengan penelitian yang mengatakan bahwa media pembelajaran mempermudah siswa dalam hal belajar (Aldila et al., 2019; Puspitorini et al., 2014). Buku ajar berbasis infografis sudah memenuhi aspek untuk dapat digunakan sebagai buku ajar sehingga dapat dijadikan media pembelajaran yang efektif (Reizal et al., 2020). Temuan penelitian lainnya menunjukkan bahwa media infografis layak dan dapat meningkatkan minat belajar 
(Mansur \& Rafiudin, 2020). Penelitian ini bertujuan untuk mengembangkan media pembelajaran biologi berupa infografis tentang sistem imun manusia. Penelitian ini sangat penting dilaksanakan mengingat bahwa materi sistenm imun manusia lebih mudah dipahami siswa apabila dibantu dengan menggunakan media pembelajaran. Dengan mengembangkan media pembelajaran berbentuk infografis akan dapat meningkatkan minat dan hasil belajar peserta didik.

\section{METODE}

Jenis Penelitian ini adalah penelitian pengembangan (Development Research) dengan menggunakan tahapan 4-D Models yang telah dimodifikasi menjadi 3 tahapan yaitu tahap Define (Pendefinisian), tahap Design (Perancangan), tahap Develop (Pengembangan). Subjek penelitian ini adalah 2 orang dosen Jurusan Biologi, dan 1 guru Biologi sebagai validator. Uji praktikalitas 35 peserta didik Kelas XI di SMAN 7 Padang dan seorang guru Biologi SMAN 7 Padang. Pengumpulan data dilakukan dengan observasi dan wawancara. Metode analisis data dilakukan dengan statistik deskriptif meliputi analisis validitas dan praktikalitas. 1) Analisis validitas, Cara mendapatkan data validasi yaitu dengan menganalisis angket yang diberikan kepada validator. Analisis validasi media pembelajaran biologi berbentuk infografis berhubungan dengan aspek kelayakan isi, kebahasaan, penyajian, dan kegrafikan. Untuk mencari nilai validitas diperoleh dari jumlah skor yang di peroeh dibagi dengan skor maksimum kemudian dikali seratus persen. 2) Analisis Praktikalitas, Cara mendapatkan data praktikalitas yaitu dengan menganalisis angket yang diberikan kepada guru dan peserta didik. Untuk mencari nilai praktikalitas diperoleh dari jumlah skor yang diperoeh dibagi dengan skor maksimum kemudian dikali seratus persen.

\section{HASIL DAN PEMBAHASAN}

\section{Hasil}

Tahap Define (Pendefinisian) Berdasarkan hasil angket yang peneliti berikan kepada peserta didik Kelas XI SMAN 7 Padang didapatkan bahwa sebagian besar peserta didik merasa kesulitan dalam memahami materi sistem imun pada manusia. Berdasarkan wawancara dengan guru terungkap bahwa peserta didik tertarik dengan adanya media pembelajaran yang memberikan gambar dan warna-warna yang cerah. Guru juga setuju dengan adanya media infografis yang bisa membuat peserta didik tertarik untuk belajar. Hasil analisis peserta didik melalui angket yang peneliti berikan diketahui bahwa umumnya peserta didik yang duduk di Kelas IX memiliki usia antara 15-17 tahun. Menurut teori belajar Piaget pada umur 11/12-18 tahun merupakan tahap operasional formal dimana ciri pokok perkembangannya sudah mampu berpikir logis, menarik kesimpulan, menafsirkan dan mengembangkan hipotesis. Pada usia ini peserta didik sudah masuk ke dalam kategori individu yang sudah mampu mengembangkan potensi psikomotornya sehingga telah terampil dalam menggunakan media termasuk media pembelajaran seperti media infografis. Analisis ini bertujuan menentukan struktur isi dalam media yang berdasarkan KI, KD dan indikator pembelajaran pada topik sistem imun pada manusia. Analisis dilakukan dengan mengidentifikasi poin utama dari sistem imun pada manusia yang disusun secara sistematis, yaitu dari materi yang bersifat ringan hingga materi yang kompleks. Berdasarkan KI, KD dan Indikator pembelajaran Kurikulum Tahun 2013, telah ditentukan poin utama dalam materi sistem imun pada manusia yaitu konsep sistem imun, organ-organ yang terlibat dalam sistem imun, sistem imun nonspesifik dan sistem imun spesifik, jenis-jenis imunitas, imunisasi, dan kelainan pada sistem imun. Analisis tujuan pembelajaran mengacu pada KD 3.14 Kurikulum Tahun 2013 tentang materi sistem imun pada manusia.

Tahap Design (Perancangan). Media pembelajaran biologi berbentuk infografis ini dirancang dengan menggunakan aplikasi Canva yang dapat diakses secara online dibantu dengan software dan website yang mempunyai fungsi berbeda masing-masingnya. Software dan website yang digunakan dalam merancang media infografis ini yaitu; (1) Photoshop berfungsi untuk mengedit foto yang akan digunakan, (2) http://waifu2x.udp.ip/ : berfungsi untuk memperbesar resolus gambar. Media pembelajaran biologi berbentuk infografis yang dikembangkan memiliki 16 halaman yang terdiri dari materi sistem imun pada manusia yang dimulai dengan materi 1 yaitu konsep sistem imun dan fungsinya, organ-organ yang terlibat dalam sistem imun, perbedaan sistem imun nonspesifik dan sistem imun spesifik, jenis-jenis imunitas, imunisasi, dan kelainan pada sistem imun. Tahap Develop (Pengembangan). Pada tahap ini dilakukan pengembangan media pembelajaran biologi berbentuk infografis. Setelah media dikembangkan, dilakukan validasi dan uji praktikalitas dari media pembelajaran biologi berbentuk infografis. Adapun hasil pengembangan media disajikan pada Gambar 1. 

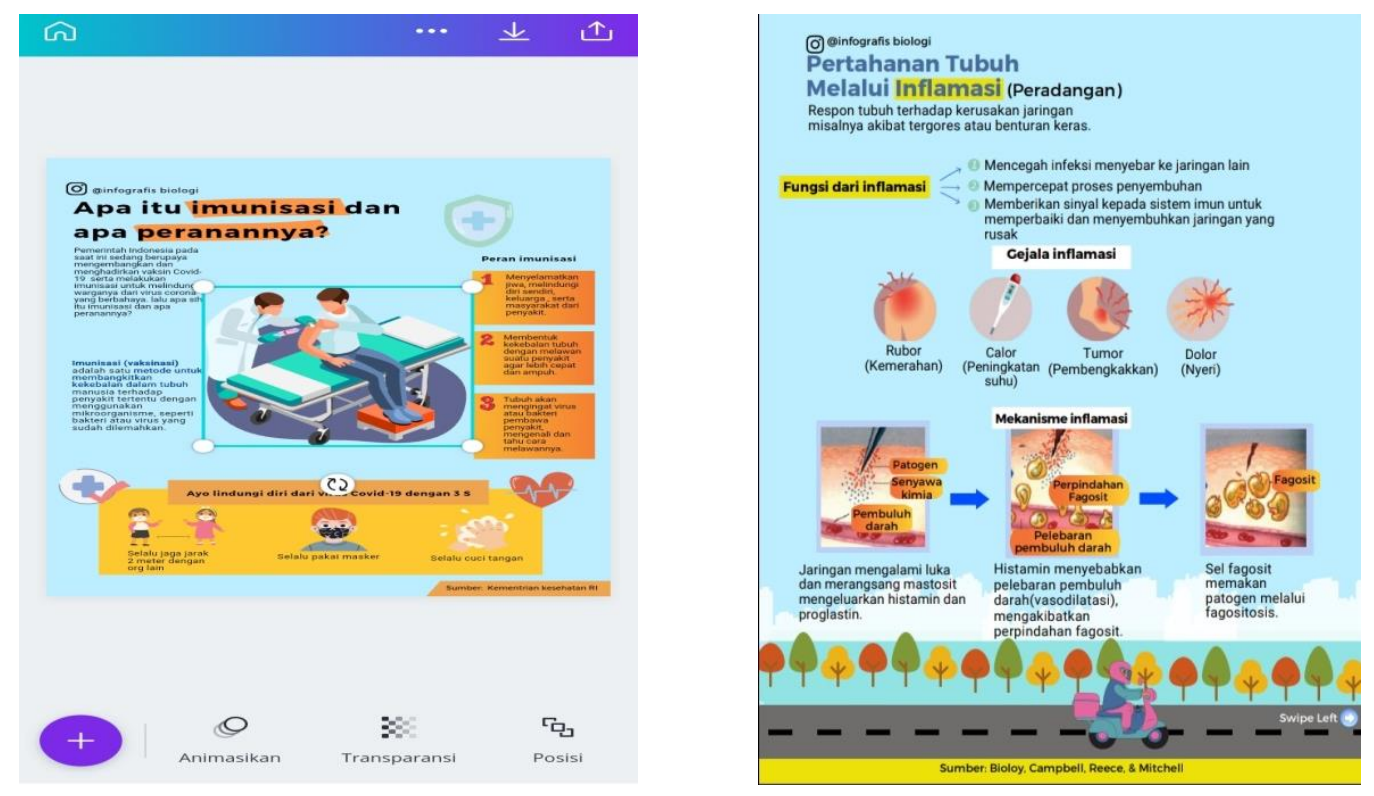

Gambar 1. Media infografis dengan aplikasi Canva.

Setelah media dikembangkan, selanjutnya media divalidasi media pembelajaran biologi berbentuk infografis. Hasil analisis angket validasi media infografis yaitu nilai kelayakan isi yaitu $90,84 \%$ (sangat valid), kebahasaan yaitu $86,67 \%$ (valid), penyajian yaitu $(90,28 \%$ ), dan aspek kegrafikan yaitu $85 \%$ (valid). Berdasarkan hasil analisis data, rata-rata validitas yaitu $88,11 \%$ dengan kategori valid. Ini memiliki kesimpulan bahwa media pembelajaran biologi berbentuk infografis yang dikembangkan valid sehingga bisa digunakan dalam proses pembelajaran. Berdasarkan hasil uji praktikalitas pembelajaran biologi berbentuk infografis dari guru berdasarkan aspek Kemudahan dalam penggunaan yaitu 87,5\% (praktis), Efisiensi waktu pembelajaran yaitu 75\% (Praktis), daya Tarik yaitu 87,5\%(Praktis) dan manfaat yaitu 85\% (Praktis). Berdasarkan hasil uji praktikalitas pembelajaran biologi berbentuk infografis dari siswa berdasarkan aspek Kemudahan dalam penggunaan yaitu $82,32 \%$ (praktis), Efisiensi waktu pembelajaran yaitu $84,64 \%$ (Praktis), daya tarik yaitu $89,14 \%$ (Praktis) dan manfaat yaitu $84,86 \%$ (Praktis). Hasil analisis data, rata-rata hasil uji praktikalitas terhadap media pembelajaran biologi berbentuk infografis oleh guru adalah 85\% dengan kriteria praktis dan peserta didik $85,24 \%$ dengan kriteria praktis sehingga dapat digunankan sebagai salah satu media pendukung pembelajaran pada materi sistem imun pada manusia.

\section{Pembahasan}

Aspek penilaian analisis angket validitas media infografis didasarkan pada 4 poin yaitu kelayakan isi, kebahasaan, penyajian. Kegrafikan yang menghasilkan kriteria valid. Pada aspek kelayakan isi, media infografis memiliki kriteria sangat valid. Aspek ini menyatakan tentang keterkaitan kompetensi inti dan dasar, kesesuaian dengan perkembangan peserta didik, kebenaran subtansi materi pembelajaran, manfaat untuk menambah wawasan, penyampaian materi secara sistematis. Berdasarkan kesesuaian kompetensi dasar dan indikator maka media infografis dapat digunakan dalam pembelajaran dan sistem kurikulum yang berlaku. Hal ini sesuai dengan penelitian yang menyatakan bahwa bahan ajar yang dikembangkan harus sesuai dengan kurikulum yang telah ditetapkan (Hidayah \& Priscylio, 2019; Hutama, 2016; Sofnidar \& Yuliana, 2018). Pada aspek kebahasaan, media infografis memiliki kriteria valid. Aspek ini menyatakan tentang keterbacaan, menggunakan kaidah bahasa yang baik dan benar, penggunaan peristilahan yang tepat, informasi disampaikan dengan jelas (Putri, 2020; Reizal et al., 2020; Syafrudin \& Sujarwo, 2019). Berdasarkan tercapainya kriteria valid menunjukkan bahwa sajian materi telah menggunakan bahasa yang tepat dan sederhana. Penelitian sebelumnya juga menyatakan bahwa media yang sesuai dengan misi dan tujuan dari sebuah indikator pembelajaran adalah media yang menggunakan bahasa yang tepat dan dapat digunakan oleh guru (Djamarah et al., 2010; Saputri \& Purwadi, 2017).

Pada aspek penyajian, media infografis memiliki kriteria sangat valid. Aspek ini menyatakan tentang kualitas keterbacaan produk, urutan sajian, kemudahan penggunaan, pemberian motivasi dan daya tarik, kelengkapan informasi, ilustrasi dan gambar. Berdasarkan penyajian media infografis telah disesuaikan dengan kebutuhan peserta didik, maka peserta didik mampu memahami konsep pembelajaran dengan baik. Pada aspek kegrafikan, media infografis memiliki kriteria valid. Aspek ini 
menyatakan tentang penggunaan jenis dan ukuran huruf, komposisi warna yang digunakan, tata letak media infografis, kesesuaian informasi dan gambar, desain tampilan (Mansur \& Rafiudin, 2020; Miftah et al., 2016; Wulandari et al., 2019). Secara keseluruhan, hasil validitas media pembelajaran biologi berbentuk infografis memiliki kriteria valid. Hal tersebut mengartikan bahwa media infografis dapat dan layak digunakan dalam proses pembelajaran di SMA. Penelitian sebelumnya juga menyatakan bahwa media infografis memenuhi kriteria layak digunakan sebagai media pembelajaran (Dewi et al., 2021). Media infografis yang dikembangkan mampu meningkatkan pemahaman siswa dan membangkitkan minat siswa untuk belajar. Media infografis mampu meningkatkan minat peserta didik untuk belajar sehingga layak dan valid digunakan dalam proses pembelajaran (Arimbawa et al., 2018; Miftah et al., 2016; Nasution \& Diansyah, 2020). Media infografis memudahkan siswa dalam memahami materi sehingga layak dan valid untuk digunakan dalam proses pembelajaran disekolah.

Pada aspek kemudahan dalam penggunaan media infografis ini memiliki kriteria praktis oleh guru dan peserta didik. Aspek ini meliputi materi yang disampaikan jelas, bahasa yang digunakan mudah difahami, huruf yang digunakan mudah dibaca. Hal ini mengungkapkan bahwa media infografis menarik dan memotivasi peserta didik sehingga sesuai digunakan dalam pembelajaran (Dewi et al., 2021; Hakim \& Ramadhan, 2020). Pada aspek efesiesnsi waktu pembelajaran, media infografis memiliki kriteria praktis oleh guru dan peserta didik. Aspek ini meliputi waktu pembelajaran media lebih efesien, siswa dapat belajar sesuai kecepatannya. Pada aspek daya tarik, media infografis memiliki kriteria sangat praktis oleh guru dan praktis oleh peserta didik. Aspek ini meliputi tampilan media infografis, tipografi, ilustrasi media infografis yang menarik perhatian peserta didik untuk belajar (Hakim \& Ramadhan, 2020; Nasution \& Diansyah, 2020). Pada aspek manfaat, media infogrfis memiliki kriteria praktis oleh guru dan peserta didik. Aspek ini menjelaskan tentang mendukung peran guru sebagai fasilitator dan membantu peserta didik memahami materi. Secara keseluruhan, untuk praktikalitas media pembelajaran biologi berbentuk infografis menyatakan kriteria praktis oleh guru dan peserta didik. Nilai ini berdasarkan pada aspek kemudahan dalam penggunaan, efisensi waktu pembelajaran, daya tarik, dan manfaat. Hal tersebut sangat berguna bagi guru dan peserta didik, karena dengan adanya media infografis ini memudahkan peserta didik dalam menambah pemahaman yang lebih baik selama pembelajaran.

\section{SIMPULAN}

Hasil review dari para ahli memperoleh klasifiasiyang baik. Media berbentuk infografis yang dikembangkan valid dan layak digunakan dalam pembelajaran. Media ini sangat baik untuk digunakan dalam pembelajaran Biologi materi sistem imun manusia. Media ini diharapkan guru dalam proses pembelajarannya menggunakan media pembelajaran agar materi yang disampaikan lebih mudah untuk dipahami oleh siswa.

\section{DAFTAR RUJUKAN}

Aldila, T. H., Musadad, A. A., \& Susanto. (2019). Infografis sebagai Media Alternatif dalam Pembelajaran Sejarah bagi Siswa SMA. Andharupa Journal, 5(1). https://doi.org/10.33633/andharupa.v5i01.2104.

Alrwele, N. S. (2017). Effects of Infographics on Student Achievement and Students' Perceptions of the Impacts of Infographics. Journal of Education and Human Development, 6(3), 104-117. https://doi.org/10.15640/jehd.v6n3a12.

Apriansyah, M. R. (2020). Pengembangan Media Pembelajaran Video Berbasis Animasi Mata Kuliah Ilmu Bahan Bangunan Di Program Studi Pendidikan Teknik Bangunan Fakultas Teknik Universitas Negeri Jakarta. Jurnal PenSil, 9(1). https://doi.org/10.21009/jpensil.v9i1.12905.

Arimbawa, Agustini, \& Santyadiputra. (2018). Pengembangan Sop Berbasis Infografis Jenis-Jenis Penelitian Untuk Perkuliahan Metodologi Penelitian Pendidikan. Jurnal Pendidikan Teknologi Dan Kejuruan, 15(1). https://doi.org/10.23887/jptk-undiksha.v15i1.12288.

Arisantiani, N. K., Putra, M., \& Ganing, N. N. (2017). Pengaruh Model Pembelajaran Childrens Learning In Science (Clis) Berbantuan Media Lingkungan Terhadap Kompetensi Pengetahuan IPA. Journal of Education Technology, 1(1). https://doi.org/10.23887/jet.v1i2.11774.

Ayuni, I. A. S., Kusmariyatni, N., \& Japa, I. G. N. (2017). Pengaruh Model Pembelajaran Talking Stick Berbantuan Media Question Box Terhadap Hasil Belajar IPA Kelas V. Journal of Education Technology, 3(1). https://doi.org/10.23887/jet.v1i3.12503.

Azizul, A., Riski, W. Y., Fitriyani, D. I., \& Sari, I. N. (2020). Pengembangan Bahan Ajar Komik Digital Pada Mater Gerak. Vox Edokasi: Jurnal Ilmiah Ilmu Pendidikan, 11(2). https://doi.org/10.31932/ve.v11i2.829. 
Berutu, M. H. A., \& Tambunan, M. I. H. (2018). Pengaruh Minat Dan Kebiasaan Belajar Terhadap Hasil Belajar Biologi Siswa Sma Se-Kota Stabat. Jurnal Biolokus, 1(2). https://doi.org/10.30821/biolokus.v1i2.351.

Dewi, A. C., Adi, E. P., \& Abidin, Z. (2021). Pengembangan Infografis Melalui Instagram Sebagai Penguatan Pemahaman Pokok Bahasan Sistem Pencernaan Manusia. JKTP: Jurnal Kajian Teknologi Pendidikan, 4(2), 119-232. https://doi.org/10.17977/um038v 4 i 22021 p 216.

Dewi, N. N. K., Kristiantari, M. . R., \& Ganing, N. N. (2019). Pengaruh Model Pembelajaran Picture And Picture Berbantuan Media Visual Terhadap Keterampilan Menulis Bahasa Indonesia. Journal of Education Technology, 3(4). https://doi.org/10.23887/jet.v3i4.22364.

Djamarah, B, S., \& Z., A. (2010). Strategi Belajar Mengajar. Rineka Cipta.

Dwipayana, I. K. (2013). Kemampuan Siswa Dalam Pelajaran Biologi Dengan Menggunakan Media Pembelajaran Berbasis Video Animasi Pada Siswa Kelas VII DI SMP Negeri 2 Singaraja Tahun Pelajaran 2011/2012. Jurnal Edutech Undiksha, 1(1). https://doi.org/10.23887/jeu.v1i1.360.

Fitriana, Lesmanawati, \& Maknun. (2014). Penerapan Pembelajaran Berbasis Inquiri Sederhana Untuk Meningkatkan Literasi Sains Siswa Pada Konsep Ekosistem Di Kelas X Ma Khas Kempek Cirebon. Scientiae Educatia: Jurnal Pendidikan Sains, 3(1). https://doi.org/10.24235/sc.educatia.v3i1.555.

Hakim, A. A., \& Ramadhan, A. (2020). Perancangan Video Infografis Siklus Hidup Nyamuk Demam Berdarah dan Cara Pencegahannya. Andharupa Journal, 6(1). https: //doi.org/10.33633/andharupa.v6i1.3120.

Handayani, N. M. D., Ganing, N. N., \& Suniasih, N. W. (2017). Model Pembelajaran Picture and Picture Berbantuan Media Audio-Visual Terhadap Pengetahuan IPA. Journal of Education Technology, 1(3), 176. https://doi.org/10.23887/jet.v1i3.12502.

Herayanti, L., Habibi, H., \& Fuaddunazmi, M. (2017). Pengembangan Media Pembelajaran Berbasis Moodle pada Matakuliah Fisika Dasar. Jurnal Cakrawala Pendidikan, 36(2), 210-219. https://doi.org/10.21831/cp.v36i2.13077.

Hidayah, D. N., \& Priscylio, G. (2019). Pengembangan Bahan Ajar Mandiri Pokok Bahasan Suhu Dan Kalor Menggunakan Software Camtasia. Journal of Teaching and Learning Physics, 4(1), 50-64. https://doi.org/10.15575/jotalp.v4i1.4093.

Hutama, F. S. (2016). Pengembangan Bahan Ajar IPS Berbasis Nilai Budaya Using Untuk Siswa Sekolah Dasar. JPI Uurnal Pendidikan Indonesia), 5(2), 113. https://doi.org/10.23887/jpiundiksha.v5i2.8359.

Krismasari, D. N. N., Kristiantari, M. G. R., \& Ganing, N. N. (2019). Pengaruh Model Pembelajaran Picture and Picture Berbantuan Media Visual Terhadap Keterampilan Menulis Bahasa Indonesia. Journal of Education Technology, 3(4), 278. https://doi.org/10.23887/jet.v3i4.22364.

Mansur, H., \& Rafiudin, R. (2020). Pengembangan Media Pembelajaran Infografis untuk Meningkatkan Minat Belajar Mahasiswa. Jurnal Komunikasi Pendidikan. https://doi.org/10.32585/jkp.v4i1.443.

Miftah, M. N., Rizal, E., \& Anwar, R. K. (2016). Pola Literasi Visual Infografer dalam pembuatan Informasi Grafis (Infografis). Jurnal Kajian Informas \&Perpustakaan, 4(1), 87-94. https://doi.org/10.24198/jkip.v4i1.11635.

Muthiadin, C., Aziz, I. R., Hajrah, \& Alir, R. F. (2020). Edukasi Dan Pelatihan Desain Infografis COVID-19 Bagi Siswa dan Guru SMAN 10 Makasar. JSasambo:Jurnal Abdimas (Journal Of Community Service), 2(3), 153-162. https://doi.org/10.36312/sasambo.v2i3.313.

Nasution, A. H., \& Diansyah, A. (2020). Pengembangan Media Berbentuk Infografis Dalam Pembelajaran Sejarah Di Tingkat Sma. Jurnal Sekolah, 4(3), 261-266. https://doi.org/10.24114/js.v4i3.18925.

Novika Auliyana, S., Akbar, S., \& Yuniastuti. (2018). Penerapan Pembelajaran Tematik Terpadu di Sekolah Dasar. Jurnal Pendidikan: Teori, Penelitian, Dan Pengembangan, 3(12), 1572-1582. https://doi.org/10.17977/jptpp.v3i12.11796.

Octaviani, S. (2017). Pengembangan Bahan Ajar Tematik Dalam Implementasi Kurikulum 2013 Kelas 1 Sekolah Dasar. EduHumaniora: Jurnal Pendidikan Dasar, 9(2), 93-98. https://doi.org//10.17509/eh.v9i2.7039.

Pambudi, B., Efendi, R. B., Novianti, L. A., Novitasari, D., \& Ngazizah, N. (2019). Pengembangan Alat Peraga IPA dari Barang Bekas untuk Meningkatkan Motivasi Belajar dan Pemahaman Siswa Sekolah Dasar. Indonesian Journal of Primary Education, 2(2), 28. https://doi.org/10.17509/ijpe.v2i2.15097.

Prabawa, D. G. A. P., \& Restami, M. P. (2020). Pengembangan Multimedia Tematik Berpendekatan Saintifik untuk Siswa Sekolah Dasar. Mimbar PGSD Undikhsa, 8(3), 479-491. https: //doi.org/10.23887/jjpgsd.v8i3.28970.

Pradilasari, L., Gani, A., \& Khaldun, I. (2019). Pengembangan Media Pembelajaran Berbasis Audio Visual pada Materi Koloid Untuk Meningkatkan Motivasi dan Hasil Belajar Siswa SMA. Jurnal Pendidikan 
Sains Indonesia, 7(1), 9-15. https://doi.org/10.24815/jpsi.v7i1.13293.

Pramana, I. P. Y., \& Suarjana, I. M. (2019). Pengaruh Model Pembelajaran Time Token Berbantuan Media Video Terhadap Hasil Belajar IPA Kelas V SD. Journal of Education Technology, 2(4), 137. https: //doi.org/10.23887/jet.v2i4.16425.

Priantini, D. A. (2020). The Development Of Teaching Video Media Based On Tri Kaya Parisudha In Educational Psychology Courses. Journal of Education Technology, 4(4). https://doi.org/10.23887/jet.v4i4.29608.

Priyanti, N. L. S., Sujana, I. W., \& Darsana, I. W. (2017). Pengaruh Keterampilan Dasar Literasi Berbantuan Media Grafis Terhadap Penguasaan Kompetensi Pengetahuan Ips Siswa Kelas Iv Sd. Journal of Education Technology, 1(2), 110. https://doi.org/10.23887/jet.v1i2.11772.

Puspitorini, Subali, \& Jumadi. (2014). Penggunaan Media Komik Dalam Pembelajaran Ipa Untuk Meningkatkan Motivasi Dan Hasil Belajar Kognitif Dan Afektif. Cakrawala Pendidikan, 33(3), 413420. https://doi.org/10.21831/cp.v3i3.2385.

Putri, A. E. (2020). Analisis Kebutuhan Bahan Ajar Berbasis Literasi Digital Nilai-Nilai Kearifan Lokal pada Tradisi Saprahan di Pontianak. Yupa: Historical Studies Journal, 3(1), 1-7. https://doi.org/10.30872/yupa.v3i1.132.

Rahma, N. A., \& Pujiastuti, H. (2021). Efektivitas Pembelajaran Daring Matematika Pada Masa Pandemi Covid-19 Di Kota Cilegon [the Effectiveness of Mathematics Online Learning During the Covid-19 Pandemic in Cilegon City]. JOHME: Journal of Holistic Mathematics Education, 5(1), 1. https: //doi.org/10.19166/johme.v5i1.3811.

Reizal, H., Agustiningsih, A., \& Hutama, F. S. (2020). Pengembangan Buku Ajar Berbasis Infografis Pada Tema Ekosistem Untuk Meningkatkan Hasil Belajar Siswa Kelas V Sd. Muallimuna: Jurnal Madrasah Ibtidaiyah, 5(2), 54-65. https://doi.org/10.31602/muallimuna.v5i2.2879.

Rofiq, A., Mahadewi, L. P. P., \& Parmiti, D. P. (2019). Pengembangan Multimedia Pembelajaran Interaktif Pada Mata Pelajaran Ips Terpadu. Journal of Education Technology, 3(3), 126. https://doi.org/10.23887/jet.v3i3.21732.

Saputri, V. A., \& Purwadi, P. (2017). Upaya Meningkatkan Motorik Kasar Anak Melalui Metode Permainan Tradisional Egrang Bathok Kelapa Pada Kelompok B Di Ra Taqwal Ilah Semarang. Paudia : Jurnal Penelitian Dalam Bidang Pendidikan Anak Usia Dini, 4(1). https://doi.org/10.26877/paudia.v4i1.1654.

Seika Ayuni, I. G. a. P. A., Kusmariyatni, N., \& Japa, I. G. N. (2017). Pengaruh Model Pembelajaran Talking Stick Berbantuan Media Question Box Terhadap Hasil Belajar Ipa Kelas V. Journal of Education Technology, 1(3), 183. https://doi.org/10.23887/jet.v1i3.12503.

Septiani, M. T., \& Hasanah, M. (2019). Media Audio Visual untuk Pembelajaran Musikalisasi Puisi. BASINDO: Jurnal Kajian Bahasa, Sastra Indonesia, Dan Pembelajarannya, 3(1), 31-37. https://doi.org/10.17977/um007v3i12019p031.

Setianingsih, I. G. A. A. A., Putra, D. K. N. S., \& Kt.Ardana, I. (2019). Pengaruh Model Pembelajaran Reciprocal Teaching Berbantuan Media Audio Visualterhadap Kompetensi Pengetahuan IPA. Journal of Education Technology, 3(3), 203-209. https://doi.org/10.23887/jet.v3i3.21827.

Sofnidar, S., \& Yuliana, R. (2018). Pengembangan Media Melalui Aplikasi Adobe Flash Dan Photoshop Berbasis Pendekatan Saintifik. Jurnal Gentala Pendidikan Dasar, 3(2), 257-275. https://doi.org/10.22437/gentala.v3i2.6761.

Suadnyana, I. N., Wiyasa, I. K. N., Ardana, I. K., Putra, D. K. N. S., \& Wulandari, I. G. A. A. (2017). Pelatihan Penyusunan Rpp Tematik Integratif Menggunakan Pendekatan Saintifik Bagi Guru-Guru Sekolah Dasar Gugus VIII Abiansemal Badung Tahun Pelajaran 2015/2016. International Journal of Community Service Learning, 1(1), 63- 66. https://doi.org/10.23887/Ijcsl.V1i1.11908.

Sulfemi, W. B., \& Mayasari, N. (2019). Peranan Model Pembelajaran Value Clarification Technique Berbantuan Media Audio Visual Untuk Meningkatkan Hasil Belajar IPS. Jurnal Pendidikan, 20(1), 53. https://doi.org/10.33830/jp.v20i1.772.2019.

Surata, I. K., Sudiana, I. M., \& Sudirgayasa, I. G. (2020). Meta-Analisis Media Pembelajaran pada Pembelajaran Biologi. Journal of Education Technology, 4(1), 22-27. https://doi.org/10.23887/jet.v4i1.24079.

Syafrudin, T., \& Sujarwo, S. (2019). Pengembangan Bahan Ajar Untuk Pembelajaran Matematika Bagi Siswa Tunarungu. Suska Journal of Mathematics Education, 5(2), 87-94. https://doi.org/10.24014/sjme.v5i2.8170.

Wisada, P. D., Sudarma, I. K., \& Yuda S, A. I. W. I. (2019). Pengembangan Media Video Pembelajaran Berorientasi Pendidikan Karakter. Journal of Education Technology, 3(3), 140. https://doi.org/10.23887/jet.v3i3.21735.

Wulandari, Sudatha, \& Simamora. (2020). Pengembangan Pembelajaran Blended Pada Mata Kuliah Ahara 
Yoga Semester II di IHDN Denpasar. Jurnal Edutech Undiksha, 8(1), 1-15. https://doi.org/10.23887/jeu.v8i1.26459.

Wulandari, V., Abidin, Z., \& Praherdhiono, H. (2019). Pengembangan Media Pembelajaran E-Book Infografis Sebagai Penguatan Kognitif Siswa X MIA. Jurnal Kajian Teknologi Pendidikan, 2(1), 3744. https://doi.org/10.17977/um038v2i12019p037. 